\title{
Might Teaching be Judgement Dependent?
}

\section{Andrew Fisher ${ }^{1} \cdot$ Jonathan Tallant ${ }^{1}$ (D)}

Received: 24 April 2019 / Revised: 11 September 2019 / Accepted: 20 September 2019 /

Published online: 4 December 2019

(C) The Author(s) 2019

\begin{abstract}
Our thesis in this paper is that consideration of Wright's account of what it is to be judgement-dependent leads us to the conclusion that teaching is judgement dependent. We begin with a consideration of Wright's account of what it is to be judgementdependent. We then make the case that teaching satisfies the conditions on what it is to be judgement-dependent. Our intention is not to delve into the independent plausibility of such a view. Our focus is simply on showing the connection between Wright's account of judgement-dependence and what it is to teach.
\end{abstract}

Keywords Judgement dependence · Teaching

\section{Introduction}

Some features of the world around us are, plausibly, judgement dependent. For example, occupants of the world may be any of (for instance) 'exciting', 'irritating', 'nauseating' or, 'red'. Whether or not some event is, say, 'exciting' is not a matter that can be adjudicated upon independently of the judgements of those that might experience the event.

Philosophically, albeit somewhat loosely, the norm within the literature is to say that a feature of the world is judgement-dependent iff it is denoted by a term such that the judgements of suitable agents in ideal conditions determine the truth of the application of these terms. Thus, it is true that something is exciting iff we judge it to be exciting under ideal conditions; it is true that something is red iff we judge it so under ideal conditions, etc. It is our judgements under those conditions that determine the truth of the judgements. Our ordinary judgements are, if true, true because they track our

Jonathan Tallant

jonathan.tallant@nottingham.ac.uk

Andrew Fisher

Andrew.fisher@nottingham.ac.uk

1 Department of Philosophy, University of Nottingham, Nottingham NG7 2RD, UK 
judgements under ideal conditions not because they 'track' judgement independent fact in the world.

Of course, other features of the world are judgement-independent. It is worth considering these briefly if only to make clear the contrast between judgement dependence and judgement independence. A good example of a judgement-independent feature of the world is 'square'. Something isn't square because we judge it so under ideal conditions. Rather something is a square if, and only if, it is a plane figure with four equal straight sides and four right angles. But if it is so, then that it is so is quite independent of whether or not we judge it to be so. The truth of judgements about squareness are thus determined by some objective, independent facts in the world and are not determined by our judgements.

There has been a good deal of work that looks to explore which features of the world are judgement-dependent, as well as a variety of accounts that seek to provide accounts of what it is to be judgement dependent. Indeed, the concept of judgement-dependence has been developed across a range of works. Wright (1987, 1988a, 1988b, 1989, 1992), Pettit (1991, 1992), Johnston (1989, 1993), and Divers and Miller (1999). ${ }^{1}$ These papers have, between them, generated discussions of, and views about, judgementdependence across a whole host of topics, including (but not limited to) the philosophy of colour, the nature of morality, intentional psychology, mathematics, and modality. We take ourselves to be adding to this literature here, expanding the range of phenomena that may plausibly be given a judgement-dependent treatment. ${ }^{2}$

Within the literature, we take Wright's account of judgement dependence to be the most prominent. Here we will argue that teaching satisfies Wright's conditions for being judgement dependent. In section 2 we rehearse Wright's conditions for being judgement-dependent. In section 3 we argue that teaching satisfies these conditions and say a little about the significance of this finding. In section 4 we conclude.

\section{Judgement-Dependence}

Following Wright (1992), a feature of the world is judgement-dependent if it satisfies the provisional equation in such a way as to satisfy three conditions - to be specified in just a moment. ${ }^{3}$

\footnotetext{
${ }^{1}$ Although there is much to be said about the links between these, we will focus purely on judgementdependence.

${ }^{2}$ There are interesting questions about how it is that we arrive at judgements. For example, it seems plausible to think that they involve interpretation. After all, it would, we think, be out of step with our everyday experience to think that judgement is simply a direct reaction to the world we encounter. This in turn would introduce more complexity, for example, presumably it would involve a discussion of intentions, and with this complex issues within the philosophy of mind (see for example Wright's (1987) account of how intention relates to judgement-dependence). Thankfully, although important for a wider project, whether judgement involves interpretation is upstream from this discussion. For we are interested in whether it makes sense to think that once an agent makes a judgement, under certain conditions, this judgement by itself determines whether the application of 'teaching' is correct. We thank an anonymous reviewer for raising this important point of clarification.

${ }^{3}$ For a more detailed exposition of Wright's work, see the full list of citations given in the reference list. We are deliberately somewhat sparse in our introduction to Wright's position. We take it to be reasonably well known in the literature.
} 
Provisional Equation:

$$
\forall x[C \rightarrow(\text { A suitable subject } s \text { judges that } P x \leftrightarrow P x)]
$$

Where ' $\mathrm{C}$ ' specifies a set of conditions usually described as 'ideal conditions'.

The conditions to be satisfied are a prioricity, substantiality, independence, and the extremal condition. We will briefly turn to unpacking these using 'exciting', our paradigmatic instance of a judgement-dependent feature of the world, as a stalking horse in order to help us explain how Wright's account of judgement-dependence is supposed to function. In section 3 we'll show how teaching satisfies these conditions.

A prioricity. If a feature of the world is judgement-dependent then we will know $a$ priori that an agent under ideal conditions making a judgement that applies the concept will track the true applications of the concept.

Illustration: consider whether or not $\mathrm{x}$ is exciting. Suppose that an agent, in ideal conditions, judges that $\mathrm{x}$ is exciting. A priori, we know that they are correct: $\mathrm{x}$ is exciting. This is all that there is to be said.

Substantiality. Specifying 'ideal conditions' can't amount to 'whatever it takes'; we must be able to go some way to offering a non-trivial description of the relevant ideal conditions.

Illustration: when specifying the ideal conditions under which we judge that $\mathrm{x}$ is exciting what we say about the ideal conditions must be non-circular and informative. Our specification of those conditions can't say anything like: 'the conditions for judgements about $\mathrm{x}$ being exciting are ideal iff they return the result that $\mathrm{x}$ is exciting'.

To make more significant inroads into the general idea, we borrow from Divers and Miller (1999: 286-7) and their discussion of the 'ideal conditions' for colour judgements. Therein, they supply the following account of ideal conditions for judgements about colours.

the subject knows which object is in question, is attentive, possesses statistically normal visual equipment, is competent with the key concept whose application is under consideration, is otherwise cognitively lucid, and is free from doubt about the satisfaction of any of these conditions; the object is in full view of the subject, is viewed in good light, is relatively proximate subject, and is stationary relative to the subject.

As should be clear, such a specification of ideal conditions is non-trivial and is certainly informative.

We will need to modify these slightly in the process of specifying what is required of ideal conditions in the case of teaching, ${ }^{4}$ but this will suffice by way of illustration of

\footnotetext{
${ }^{4}$ Divers and Miller (1999) engage in a similar exercise when discussing whether or not mathematical truths might be thought of as judgement-dependent.
} 
the kind of way in which substantiality might be satisfied. We shall now move on to consider the remaining conditions.

Independence. whether the ideal-conditions for judgements about $\mathrm{p}$ obtain must be logically independent of whether or not $\mathrm{p}$ is true.

Illustration: suppose that we are considering the term 'exciting'. The judgementdependent account is intended to give us the truth-conditions for sentences about whether or not specific events are exciting. A part of those truth-conditions include claims about ideal conditions. Those truth-conditions cannot, then, presuppose that particular claims about events being exciting are true - else we would have a regress. And, of course, this means that our specification of what it is for conditions to be ideal cannot presuppose the truth of claims about what is, and what is not, exciting.

The extremal condition. There can't be a better way of explaining why we can know a priori that judgements made under ideal conditions will be true.

Illustration: there is no obvious way to explain why the judgement of an observer in ideal conditions will judge that $\mathrm{x}$ is exciting when and only when it is exciting, other than by supposing that being exciting is a judgement dependent property.

We should say a little more, for the extremal condition can seem a little opaque at a first pass. Consider, for instance, the case of pain. Typically, judgements about being in pain are not treated as judgement-dependent. Whether or not a subject is in pain is determined, not by judgement, but by other facts - including those facts about their physiology. Nonetheless, it's easy enough to see that they would satisfy the a prioricity condition: if an agent in ideal conditions judges that they are in pain then, a priori, it is true that the agent is in pain. Furthermore, it will likely satisfy the other conditions as well, substantiality and independence. However, these facts, in themselves, do not allow us to 'read off' that judgments about being in pain are judgement-dependent. This is because we haven't, as of yet, ruled out there being another better explanation for judgements about pain meeting these conditions.

And, as it turns out, there is another explanation for the covariance of the truth of claims about agents being in pain, and their judgements that they are in pain. Simply, the explanation is that someone who is in pain does not need to form a judgement to that effect, at all. Pain is "something whose occurrence requires no capacity of judgement on the part of the subject" (Wright 1992: 123). The detection of pain in all cases causes an awareness of pain, and hence the judgement that $\mathrm{x}$ is in pain then follows. That appears to be a better, alternative explanation of why judgement about $\mathrm{x}$ being in pain meets the other conditions, than the view that pain is judgement dependent, which means we aren't entitled to claim that such judgements are judgement-dependent, simply on the grounds that they meet the other conditions. ${ }^{5}$

\footnotetext{
5 At least, that's the prevailing view and here we only illustrate it. As elsewhere in the paper, we take ourselves to be presenting rather than critiquing Wright's view. Someone disagreeing with Wright's account of judgement-dependence is not our intended target.
} 
Of course, there are concerns with this account of judgement dependence. Nonetheless, we take it to be the mainstream account and it is the one that we will adopt from this point on. We now want to turn our attention to showing that, conditional on the adoption of this account of judgement-dependence, teaching is judgement-dependent.

\section{Teaching Is Judgement-Dependent}

The structure of this section unimaginatively mimics that of the preceding. In each of the following sub-sections we show that teaching satisfies the account of judgementdependence that we sketched in section 2 of the paper. In 3.1 we run together each of the provisional equation, a prioricity and extremality, since we think that each is reasonably uncontroversial.

\subsection{Provisional Equation, a prioricity and Extremality}

First up, we think that teaching satisfies the provisional equation: $\forall x[C \rightarrow$ (A suitable subject $s$ judges that $P x \leftrightarrow P x)]$. That is:

Judgement-Dependent Teaching (JDT):

$$
\forall x[C \rightarrow(\text { A suitable subject } s \text { judges that } x \text { is teaching } \leftrightarrow x \text { is teaching })] \text {. }
$$

To persuade the reader that this is plausible we shall move to explaining why we think that JDT satisfies the provisional equation in such a fashion as to also satisfy the four conditions of a prioricity, substantiality, Independence, and extremality.

According to the a prioricity condition, there must be a priori covariance of the judgements of ideal observers and the truth of those judgements. So far as we can see, if a competent judge under ideal conditions judges that an agent is teaching, then then that agent is teaching. A priori, there is covariance of best opinions and truth.

We find it hard to definitively make the case that this is so, and that the JDT satisfies the a prioricity condition, but here is a case that goes some way to motivating our thinking on this score. Suppose that we set up a case located in a classroom setting where one agent leads a session. They give instruction to those in front of them. Things are said, things are written. Over and above the judgements of an observer in ideal conditions, to what could we appeal to determine whether or not that (underspecified) case constituted teaching? ${ }^{6}$ If an observer who is ideally placed (they are genuinely in ideal conditions - more of which below) judges that teaching has occurred, then it seems to us that, a priori, it follows that teaching has occurred. That being so, there is $a$ priori covariance of the judgements of ideal observers about teaching and the truth of judgements about teaching.

\footnotetext{
${ }^{6}$ We concede, of course, that an occupant of the room who is not paying attention (perhaps because they are disinterested or similar) may not judge that they have been taught. That is entirely consistent with what we say. We are not committed to any old judgements being determinative of whether or not teaching has occurred. As with all judgement-dependent accounts of some feature of the world, we require that the judge be in very specific conditions. See below for discussion of how we imagine these conditions being spelled out in the case of teaching.
} 
And, what's more, it looks as if teaching will satisfy extremality. We cannot think of any better explanation for the covariance of the judgements of competent judges under ideal conditions judging that $\mathrm{x}$ is teaching and $\mathrm{x}$ 's in fact teaching. What other kinds of explanation might we offer? What needs to be explained is how we are able to move a priori from the realisation that an agent in ideal conditions judges that ' $\mathrm{x}$ is teaching' to the truth of ' $x$ is teaching'. Such explanations are hard to come by. Certainly, the case looks utterly unlike the case of pain that we discussed above where agents have immediate access to their pain experiences, but where we do not think that pain is judgement-dependent.

To give the reader a flavour of how putative stories might go, we here pivot to considering two- both drawn from the literature on the philosophy of education. One might be minded to suppose that teaching consists in the intentions of the putative teacher. That is, that $\mathrm{x}$ is to be regarded as teaching iff $\mathrm{x}$ intends to teach. Call this the 'intentional view'. Or, we might suppose that $\mathrm{x}$ has taught $\mathrm{y}$ iff $\mathrm{y}$ has learned from $\mathrm{x}$. Call this the 'learning view'. We don't see how either the intentional or learning view will satisfy the extremal condition. Even an observer in ideal conditions will not have unfettered access to the inner cognitive machinations of either putative teacher or putative learner, so it cannot be this that our ideal observer is trading upon in forming their view that teaching has occurred, and so it cannot be this that is generating the necessary co-variance. That being so, we don't see how we can exploit either the intentional view or the learning view to provide a better explanation of the covariation of the a priori judgements of ideal observers that teaching has occurred and teaching having occurred. And, if that's right, then that leaves the judgement dependent view well placed.

\subsection{Substantiality}

We can fill out the ideal conditions for judgements about teaching non-trivially — at least, we can do so as well as we can for any judgement-dependent account of some feature of the world. Some of the conditions we will borrow from the colour case, presented above. To wit:

the subject is attentive, possesses statistically normal visual equipment, is competent with the key concept whose application is under consideration, is otherwise cognitively lucid, and is free from doubt about the satisfaction of any of these conditions

We take it that these conditions are self-explanatory: we wish our ideal conditions to include a subject that is paying attention, familiar with the concepts, and who is cognitively and visually functioning in a more or less normal fashion. It is certainly easy enough to see how failure to satisfy these conditions could generate less than ideal conditions for judgement.

We also wish to add a slight modification to some other conditions described above.

First, we must recognize that the accuracy of judgements about teaching are not dependent only on what can be seen. Judgements about teaching will, in normal classroom environments, also require judgements about audition. Further, where 
judgements about colour require only that the putatively coloured object be seen, we will have to allow our observer to observe both putative teacher(s) and putative learner(s). Taking both of those thoughts into account, it would be tempting to offer the following account of ideal conditions.

the subject knows which objects are in question (that are doing the putative teaching and putative learning - if there is any such going on), the objects are in full view of the subject and can be heard by the subject; are viewed in good light and quiet conditions, is relatively proximate to the objects and are nearly stationary relative to them.

The reader will recognize that these are only a modest departure from the conditions described in reference to the colour case.

But we think that this would, ultimately, be a little too narrow. As well as being able to hear what is said and see the environment and putative teachers and learners, judgements about learning may also depend upon other factors. Suppose, for instance, that the putative teacher is giving a talk on the olfactory properties of wine. In that case, it may well not be sufficient for the observer in ideal conditions to simply see and hear both putative teacher and putative learner in order to provide us with the judgementdependence that would deliver the facts of the matter as to whether teaching is occurring: they may require olfactory access to the scenario, as well. And, indeed, for reasons with a similar structure, we might well want to insist that the ideal conditions make reference to all sensory faculties.

But there is a question, then, of how to make reference to those faculties. For instance, suppose we modify our proposed account as follows:

the subject knows which objects are in question (that are doing the putative teaching and putative learning - if there is any such going on), the objects are in full view of the subject and can be heard by the subject; are viewed in good light and quiet conditions; are smelled and tasted and touched by the putative learners without interference; are relatively proximate to the objects and are nearly stationary relative to them.

However, this seems quite an implausible rendering of the ideal conditions.

In order to properly specify the ideal conditions, we need to think in terms both of the putative teacher and learner, to which the judge must have access to in order to be considered to be in ideal conditions, but also to any communicative props that are being used. For instance, suppose that the putative teacher is using a handout. If the putative teacher makes what sounds like crucial reference to the handout, but the handout is blank, or contains entirely irrelevant information, or what have you, then it seems at least plausible that teaching will fail to take place (depending on the details of the case, of course). That being so, we think that we must expand what constitute ideal conditions to include perceptual access to anything that putative learners have access to. Thus, if $\mathrm{x}$ and $\mathrm{y}$ are having a conversation with the aid of props, and we wish to determine whether or not $\mathrm{x}$ is teaching $\mathrm{y}$, then such a judgement would ultimately turn 
on the judgements of observers who have unimpeded perceptual access to any communicative prop to which y has access.

Last, but my no means least, in specifying these conditions we must allow for the possibility that teaching and learning can take place in 1:1, 1: many, many: many, and many: 1 scenarios. (Individuals can teach individuals, individuals can teach groups; groups can teach groups, and groups can teach an individual.) To accommodate that, in the following we quantify plurally, and offer this as our semi-formal account that includes a full specifications of the ideal conditions.

JDT: $\forall \mathrm{xx}, \forall \mathrm{yy}, \mathrm{xx}$ teach yy iff a judge, J, would form the judgement that $\mathrm{xx}$ teach yy in conditions such that $\mathrm{J}$ knows that it is $\mathrm{xx}$ and yy that are under consideration; $\mathrm{xx}$ and yy are in full view of $\mathrm{J}$ and can be heard by the $J$; $\mathrm{xx}$ and yy viewed in good light and quiet conditions; further, that any communication props being used by $\mathrm{xx}$ to communicate with yy are such that $\mathrm{J}$ has the same perceptual access to them as yy; $\mathrm{J}$ is relatively proximate to $\mathrm{xx}$ and yy and are nearly stationary relative to them.

This completes our analysis of the ideal conditions.

\subsection{Independence}

In specifying the ideal conditions, we do not think that we have (in any way) presupposed truths about teaching. In the ideal conditions given, in JDT we specify a range of factors around communication, perceptual access, and so on. We are not, in doing so, trading upon or presupposing the truth of any claims about teaching. That being so, we think that we have satisfied independence.

And that, of course, completes this section. We have shown that teaching satisfies each of Wright's conditions on judgement dependence. We conclude that teaching is judgement dependent.

\section{Challenges}

Before closing, however, we wish to offer a brief and very general response to those who hold a different view of the nature of teaching - plausibly, versions of either the intentional or learning views that we sketched in section 3. For, to this point, it might strike the reader as absurd to think of teaching as judgement dependent. Perhaps it seems that, quite independently of this talk of a provisional equation, and the satisfaction of other conditions, it is clear to the reader (at least at a first pass) that teaching just isn't like that. Teaching isn't like excitement. It isn't like colour. And, once we reflect upon matters, it's clear that teaching is closer to the ways in which it's described by either the intentional view of the learning view.

Here we offer four quick thoughts. First, we find the general shape of the intentional view and learning view to be slightly out of kilter with how we think of teaching. The general shape of the intentional view is that $\mathrm{x}$ is to be regarded as teaching iff $\mathrm{x}$ intends to teach. But that, it seems to us, cannot be right. We already find ourselves in a world 
with Robotic teachers in the classroom, ${ }^{7}$ and AI capable of taking on the role of teacher in specific contexts. ${ }^{8}$ Such Robots and AIs do not have intentions (at least, not yet). Thus, intention doesn't do automatically seem to do the job. Equally, the learning view has it that $\mathrm{x}$ is to be regarded as teaching iff $\mathrm{y}$ has learned from $\mathrm{x}$. But, again, that seems too fast. Both authors have (sadly) taught sessions where no student has learned. Equally, if a child slips on an icy puddle, pulling a muscle in the process, and so learns what it feels like to pull a muscle, we do not think that we can definitively say that they have been taught what it feels like to wrench their leg in such a way as to pull a muscle. To be sure, there are refinements to each of these views that are considerably more sophisticated-we don't dwell on the details since within each grouping there is variation as to the details. But that is consistent with our strategy here. Our imagined opponent is stating that, at a first pass, teaching just doesn't feel like it's judgement dependent. To which, we reply, that at a first pass it doesn't seem like teaching is dependent on learning or intention, either. Generally, then, we think that we ought to be wary of such first pass judgments.

Second, stepping past those judgements, we note that we left the defender of such views (the intentional view and the learning view) a challenge in 3.1: explain the covariance of a priori judgements that teaching has occurred with the fact that teaching has occurred, with an explanation better than that offered by the judgement dependent account. We don't see that such an account is available, but we would welcome work on this score.

Third, we should try briefly to clarify the precise nature of what we're claiming here. To begin, here is what we are not claiming. We are not claiming, definitively, that teaching is judgement dependent. All that we are doing is suggesting that it appears that teaching appears as of it satisfies Wright's criteria. More work must be done to test this hypothesis. In the final analysis, perhaps it will turn out that Wright's account is the wrong one, or else that a fully developed account of (for instance) the intentional view will turn out to be correct. We do not know how things will go. Our conclusion is merely the relatively tentative claim that it appears that teaching satisfies Wright's conditions.

Fourth, and finally, we close with a point that we concede to be a little rhetorical, and so perhaps less persuasive, but that we feel obliged to make. Here is the basic thought. If a competent judge under ideal conditions judges that an agent is teaching, then it seems hard to see that we have legitimate grounds to doubt their judgement. ${ }^{9}$ Facts that are independent of ideal conditions do not seem to be required to specify which judgements about teaching are the correct ones. It is unclear to us what more could be said. A short discussion of judgement independent features of the world may be of use, for in those cases it's easy to see that there $i s$ more that can be said.

It is easy to see that if someone judged a three-sided object to be a square, we could point out the error with reference to existing geometrical definitions and the lack of relevant structure in the world. But if a competent judge in ideal conditions, judged an

\footnotetext{
$\overline{7}$ https://www.ft.com/content/f3cbfada-668e-11e7-8526-7b38dcaef614

${ }^{8} \mathrm{https}$ //singularityhub.com/2016/05/11/ai-teaching-assistant-helped-students-online-and-no-one-knew-thedifference/\#sm.0000c6p4rctugfgdtwt184x1 fm7zk

${ }^{9}$ It might help the reader here to note that this isn't about whether the teaching is any good. In particular, it is possible on our account that a teacher is teaching something clearly false but still be judged to be teaching under ideal conditions.
} 
agent to be teaching them, and we disagreed, we can't make a comparable move. Indeed, it is unclear to us that there could be a structure in the world, akin to geometric structure, to which the term teaching is latching on. Showing that there is no $\mathrm{x}$ (in this case, no structure in the world, akin to geometric structure, to which the term teaching is latching on) is hard. We don't think that an argument in favour of any property being regarded as judgement-dependent can ever definitively rule out the possibility that there might be some other relevant structure in the world. The best that we can do is to rule out some obvious options.

So what could our opponent say, of a given scenario, to suggest that the judgments of an ideal observer could lead us astray? Well, our opponent could argue that no learning has taken place in a given scenario, or that the putative teacher did not in fact intend to teach, and so that the ideal observer must be wrong. The details of the case don't matter to us here. What strikes us about this suggestion is that it seems intuitively false. We concede, of course, that this is a bare-faced appeal to intuition, but, to the extent that we think intuitions are of value in philosophy (and some do), we think the point worth making. If the ideal observer has seen what is going on in the classroom, then it seems intuitive to us that they have exhausted their epistemic duty when it comes to determining whether or not teaching has occurred. Crudely, what matters is what goes on where the people are, not what goes on in their heads.

\section{Conclusion}

There has been considerable ink-spilled over the question of whether or not particular kinds of feature of the world are judgement-dependent. In this paper, we find ourselves shadowing that literature. We suggest that, if Wright's account of judgement dependence is correct, then we have reason to think that teaching is judgement-dependent. We think that this is a surprising result. Certainly, no such view has been held within the philosophical literature on education. To be sure, much more needs to be done to determine whether the resulting account of teaching has the kinds of theoretical virtue that we would typically seek in our preferred theory that provides us with an account of the nature of teaching. But that is work for another time. Our more modest aim in this paper is simply to establish that, by the lights of Wright's account, teaching is judgement-dependent.

Open Access This article is distributed under the terms of the Creative Commons Attribution 4.0 International License (http://creativecommons.org/licenses/by/4.0/), which permits unrestricted use, distribution, and reproduction in any medium, provided you give appropriate credit to the original author(s) and the source, provide a link to the Creative Commons license, and indicate if changes were made.

\section{References}

Divers, J., \& Miler, A. (1999). Arithmetical Platonism: Reliability and Judgement-dependence. Philosophical Studies, 95, 277-310.

Johnston, M. (1989). Dispositional theories of value. Proceedings of the Aristotelian Society, 63, 139-174. Johnston, M. (1993). Objectivity refigured: Pragmatism without Verifica tionism'. In J. Haldane \& C. Wright (Eds.), Reality, representation, and projection (pp. 85-130). Oxford: Oxford University Press.

Pettit, P. (1991). Realism and response-dependence. Mind, 100, 597-626. 
Pettit, P. (1992). The common mind: An essay on politics, Psychology, Society. Oxford: Oxford University Press.

Wright, C. (1987). On making up One's mind: Wittgenstein on Intention. In P. Weingartner \& G. Schurz (Eds.), Logic, science, and epistemology (pp. 291-404). Vienna: Holder-Pichler-Tempsky.

Wright, C. (1988a). 'Moral values, projection, and secondary Qualities', proceedings of the Aristotelian society. Supplementary, 62, 1-26.

Wright, C. (1988b). Realism, Antirealism, Irrealism, Quasi-Realism. Midwest Studies in Philosophy, 12, 2549.

Wright, C. (1989). Wittgenstein's rule-following considerations and the central project of theoretical Linguistics. In A. George (Ed.), Reflections on Chomsky (pp. 233-264). Oxford: Blackwell.

Wright, C. (1992). Truth and objectivity. Cambridge: Harvard University Press.

Publisher's Note Springer Nature remains neutral with regard to jurisdictional claims in published maps and institutional affiliations. 